\title{
Salinity and drought-induced methylglyoxal detoxification in Brassica spp. and purification of a high active glyoxalase I from tolerant genotype
}

\author{
Md. Shahadat Hossain ${ }^{1,3}$, Mirza Hasanuzzaman ${ }^{2 *}$, Md. Ekramul Hoque ${ }^{1}$, Homayra Huq ${ }^{1}$ and Md. \\ Motiar Rohman ${ }^{3 *}$
}

\author{
${ }^{1}$ Department of Biotechnology, Faculty of Agriculture, Sher-e-Bangla Agricultural University, Sher-e-Bangla \\ Nagar, Dhaka 1207, Bangladesh \\ ${ }^{2}$ Department of Agronomy, Faculty of Agriculture, Sher-e-Bangla Agricultural University, Sher-e-Bangla Nagar, \\ Dhaka 1207, Bangladesh \\ ${ }^{3}$ Molecular Breeding Laboratory, Plant Breeding Division, Bangladesh Agricultural Research Institute, Gazipur, \\ Bangladesh
}

*Corresponding author: mhzsauag@yahoo.com; motiar_1@yahoo.com

\begin{abstract}
This experiment was conducted to study the role of glyoxalase system in conferring salinity and drought stress in Brassica spp. Two Brassica genotypes viz. BARI Sharisha16 (tolerant) and Tori7 (susceptible) were exposed to salt ( $\left.16 \mathrm{dS} \mathrm{m}^{-1}\right)$ and drought for 2, 4 and 6 days. The comparative study of two Brassica genotypes under salinity and drought stresses revealed that BARI Sharisha16 is more tolerant than Tori7 in both stresses. Under drought stress and salinity stress, Gly I activity increased significantly in both genotypes. Notably, concomitant increased activities of Gly I and Gly II with increased methylglyoxal (MG) suggested their role in MG detoxification in Brassica Spp. At six-day of salt stress, it was remarkable that Gly I and Gly II activities were 49 and $36 \%$ higher in BARI Sharisha16 than Tori7. In addition, Gly I and Gly II activities were 24 and $21 \%$ higher in BARI Sharisha16 than Tori7 after sixth day of drought, and hence, using different column chromatography Gly I was purified from BARI Sharisha16 seedlings. In purification, the fraction eluted from affinity chromatography showed specific activity of $173.51 \mu \mathrm{M} \mathrm{min}^{-1} \mathrm{mg}^{-1}$ protein. In SDSPAGE, the purified Gly I protein migrated as a single band on with an apparent molecular mass of $27 \mathrm{kDa}$. In final purification, the recovery of Gly I activity was $0.38 \%$ along with purification fold 112.7 . In this study, role of glyoxalase system in detoxification of MG was observed and subsequently, Gly I was purified from tolerant genotypes.
\end{abstract}

Keywords: Abiotic stress; glyoxalase system; methylglyoxal; salinity; water deficit.

Abbreviations: BSA_ Bovine serum albumin; EDTA_ Ethylenediaminetetraacetic acid; GSH_ Reduced glutathione; Gly I_ Glyoxalase II; Gly II_ Glyoxalase II; GST_ Glutathione S-transferase; $\mathrm{MG}_{-}$Methylglyoxal; PAGE _ Polyacrylamide gel electrophoresis; ROS_Reactive Oxygen Species; SDS_ Sodium Dodecyl Sulfate; SLG_S-D -lactoylglutathione

\section{Introduction}

Crop plants being sessile expose to a number of adverse condition known as abiotic stress including salinity, water deficit, extremely high or low temperatures, toxic metals, waterlogging, elevated ozone, and ultraviolet radiation which adversely affect proper growth, metabolism and productivity of crop plants. Recent episodes of climate changes make the conditions worse. Abiotic stresses result in a series of physiological changes in plants that adversely affect the yield and even death. Reactive oxygen species (ROS) and methylglyoxal (MG) production in plant cell is the ultimate result under any kind of abiotic stresses (Singla-pareek et al., 2006; Hasanuzzaman et al., 2014; Nahar et al., 2016). Methylglyoxal is a highly toxic compound that produces under abiotic stress. It can inactivate the vital defense system causing metabolic disorder and cell death by reacting with proteins, lipids, and nucleic acid (Kaur et al., 2014; Nahar et al., 2015; Rahman et al., 2015).

During conversion of glyceraldehyde 3-phosphate (G3P) from dihydroxyacetone phosphate (DHAP) in glycolysis, MG is formed spontaneously in plants by non-enzymatic mechanisms under physiological conditions (Espartero et al., 1995; Yadav et al., 2005a). The rate of glycolysis increases under stress conditions, leading to an imbalance (in the initial and latter five reactions) in the pathway. Triose phosphates are very unstable metabolites, and removal of the phosphoryl group by $\beta$-elimination from 1,2 -enediolate of these trioses leads to the formation of MG (Yadav et al., 2005b). Therefore, MG production is an unavoidable consequence during stress. From G3P and DHAP, MG can also be formed enzymatically by triosephosphate isomerase that removes phosphate to yield MG (Silva et al., 2013).

The Glyoxalase system is ubiquitous in nature and consists of two enzymes: Glyoxalase I (Gly I, EC 4.4.1.5) and Glyoxalase II (Gly II, EC 3.1.2.6). These two enzymes catalyze 2-oxoaldehydes coordinately to convert into 2hydroxyacids when reduced glutathione used as a cofactor (Silva et al., 2013). The reaction is catalyzed by Gly I and Gly II (Hoque et al., 2007; Nahar et al., 2016) (Fig 1). Methylglyoxal is a primary physiological substrate for Gly I (Kalapos, 1999; Hasanuzzaman et al., 2014). The Glyoxalase system has been found to be involved in protection against 
MG induced cytotoxicity under various abiotic stresses and regulation of cell division and proliferation (Kaur et al., 2014). These properties of glyoxalase system make it an important tool for crop improvement against abiotic stresses. Understanding the importance of glyoxalase system in protection of plants under stress condition, this study was designed to investigate the role of glyoxalase system in contrast to plants of Brassica spp. under salinity and drought stresses. Glyoxalase system was studied in two Brassica spp. Finally, glyoxalase I enzyme was purified from BARI Sharisha16 which is a moderately saline tolerant genotype.

\section{Results}

\section{Methylglyoxal level in Brassica plants under salinity stress}

To check whether the upregulation of MG happened in plants in response to various stress duration, its level was measured in the seedlings under untreated control as well as various salinity stress condition. Salinity stress increased MG level sharply with the duration of salinity stress in both genotypes (Fig 2A). After 2-day of stress, MG level increased almost $103 \%$ in BARI Sharisha16 compared to control. At 4-day stress, MG level increased by $110 \%$ and $25 \%$ over control in BARI Sharisha16 and Tori7, respectively, while at 6- day, the increments were $136 \%$ and $61 \%$ over control in BARI Sharisha16 and Tori7, respectively.

\section{MG level under drought stress}

Methylglyoxal level increased with the duration of drought stress. Under control condition, MG level was higher in Tori7 than BARI Sharisha16. Unlike saline stress, MG contents were higher in Tori7 as compared to BARI Sharisha16 under drought stress and the contents were significantly higher in Tori7 than BARI Sharisha16 at 4 and 6- day (Fig 2B).

\section{Gly I activity under salinity stress}

The activities of Gly I in BARI Sharisha16 and Tori7 significantly increased under salinity stress at various durations (Fig 3A). After 2-day of stress, Gly I activity increased only in BARI Sharisha16 which was $41 \%$ higher than control. The activity further increased in time dependent manners. However, the activity was always higher in BARI Sharisha16 than Tori7 (Fig 3A).

\section{Gly I activity under drought stress}

Drought stress significantly increased the Gly I activities in BARI Sharisha16 and Tori7 (Fig 3B). After 2-day of drought stress, Gly I activities did not change significantly in BARI Sharisha16 and Tori7, compared to their respective control. At 4-day of drought stress, Gly I activity increased $76 \%$ and $32 \%$ over control in BARI Sharisha16 and Tori7, respectively. At 4-day and 6-day of drought stress, Gly I activities were higher in BARI Sharisha16 than Tori7.

\section{Gly II activity under salinity stress}

Gly II activities were increased under salinity stress both in BARI Sharisha16, and Tori7 (Fig 4A). Higher Gly II activity found in both stresses compared to control. At 2-day salinity stress, Gly II activity increased 145 and 52\% in BARI Sharisha16 and Tori7 respectively. Noticeably, at 2, 4 and 6day of salinity stress, higher Gly II activity found in BARI Sharisha16 than Tori7.

\section{Gly II activity under drought stress}

There was a significant increase in Gly II activity in response to drought stress (Fig 4B). A sharp increase of Gly II activity $(191 \%$ and $93 \%)$ was observed in BARI Sharisha16 and Tori7 over respective control due to salinity stress within 2 days. At 4-day of drought stress, Gly II activities increased $189 \%$ and $86 \%$ in BARI Sharisha16 and Tori7, accordingly over control. Though Gly II activity slightly increased after 6 day of drought stress in both genotypes, the changes were not significant.

\section{Purification of Gly I}

Since Gly I was found to increase considerably under stress, an attempt was taken to purify the Gly I from BARI Sharisha16. The soluble protein fraction prepared from $50 \mathrm{~g}$ fresh seedlings was precipitated by $65 \%\left(\mathrm{NH}_{4}\right)_{2} \mathrm{SO}_{4}$ and the dialysate was applied on DEAE-cellulose column chromatography (i.d. $1.7 \times 20 \mathrm{~cm}$ ) and eluted with a liner gradient of $\mathrm{KCl}(0-0.2 \mathrm{M})$ Fig 5. Total 140 fractions, each containing $5 \mathrm{ml}$, were collected and Gly I activity and absorbance at $280 \mathrm{~nm}$ of each fraction were measured. Gly I peak eluted at $76 \mathrm{mM}$ of $\mathrm{KCl}$ (Fig 5). The fractions containing high Gly I activity was collected from the peak and pooled for measuring its activity. Among them, Gly I showed total activity of $4.31 \mathrm{mmol} \mathrm{min}^{-1}$ with purification fold 9.23 and recovery of activity $3.73 \%$ (Table 1 ). The Gly I pools were applied on another DEAE column (DEAEcellulose chromatography-2) again for further purification. Again, one Gly I peak eluted at around $76 \mathrm{mM}$ of $\mathrm{KCl}$ (Fig 6). The Gly I activities of each fraction towards model substrate MG and absorbance at $280 \mathrm{~nm}$ were measured. The high active fractions were pooled for further purification. The pooled sample $(15 \mathrm{ml})$ showed total activity of $2.3 \mathrm{mmol}$ $\mathrm{min}^{-1}$ with purification fold 19.8 and recovery $2.06 \%$ (Table 1).

The active Gly I pools from DEAE chromatography-2 were applied on an affinity column chromatography of $S$ hexylglutathione-agarose to complete the purification. The Gly I sample was passed through the column following $10 \mathrm{ml}$ $0.2 \mathrm{ml} \mathrm{KCl}$ for washing. The Gly I was eluted with $15 \mathrm{ml} \mathrm{S}$ hexylglutathione. Gly I activity and absorbance $\mathrm{A}_{280}$ of affinity fractions were taken (Fig 7). The active fractions were pooled and dialyzed in B buffer overnight. The active fractions had specific activity $173.7 \mu \mathrm{mol}^{-1} \mathrm{mg}^{-1}$ protein, total activity 0.44 , purification fold 113 and recovery $0.38 \%$ (Table 1). The purities and molecular masses of the purified Gly I were examined by sodium dodecylsulfatepolyacrylamide gel electrophoresis (SDS-PAGE). The silver staining and CBB staining of the purified Gly I indicated that purified Gly I were highly purified and migrated as a single band on SDS-PAGE with an apparent molecular mass of 27 $\mathrm{kDa}$ (Fig 8A, B).

\section{Discussion}

It was observed that level of MG was higher under both stresses than control and the level increased with the increase in the duration of stresses (Fig 2A, B). Methylglyoxal is synthesized naturally by three enzymes: methylglyoxal synthase; cytochrome P450 IIE1 isozyme and amine oxidase participating in glycolytic bypass, acetone metabolism and amino acid breakdown, respectively. Removal of the phosphoryl group of triose phosphates produced during 
Table 1. Summary of purification of Gly I from Brassica.

\begin{tabular}{lcccccc}
\hline Purification steps & $\begin{array}{c}\text { Total } \\
\text { volume } \\
(\mathrm{ml})\end{array}$ & $\begin{array}{c}\text { Total } \\
\text { protein } \\
(\mathrm{mg})\end{array}$ & $\begin{array}{c}\text { Total activity } \\
\left(\mathrm{mmol} \mathrm{min}^{-1}\right)\end{array}$ & $\begin{array}{c}\text { Specific } \\
\text { activity } \\
\left(\mu \mathrm{mol}^{-1} \mathrm{mg}^{-1}\right. \\
\text { protein })\end{array}$ & $\begin{array}{c}\text { Purification } \\
\text { fold }\end{array}$ & $\begin{array}{c}\text { Yield of } \\
\text { activity } \\
(\%)\end{array}$ \\
\hline Crude protein & 192 & 375.36 & 115.68 & 1.54 & 1 & 100 \\
$\left(\mathrm{NH}_{4}\right)_{2} \mathrm{SO}_{4}$ precipitate & 35 & 200.07 & 97.27 & 2.43 & 1.57 & 84.08 \\
DEAE-cellulose-1 & 23 & 6.06 & 4.31 & 14.22 & 9.23 & 3.73 \\
DEAE cellulose-2 & 15 & 1.56 & 2.38 & 30.51 & 19.80 & 2.06 \\
$S$-hexylglutathione- & 5 & 0.051 & 0.44 & 173.74 & 112.7 & 0.38 \\
agarose & & & & & & \\
\hline
\end{tabular}

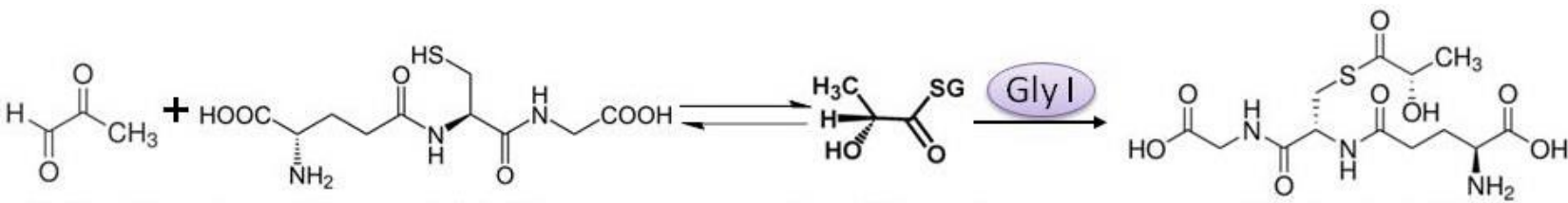

Methylglyoxal Reduced glutathione

Hemithioacetal

S-D-Lactoylglutathione

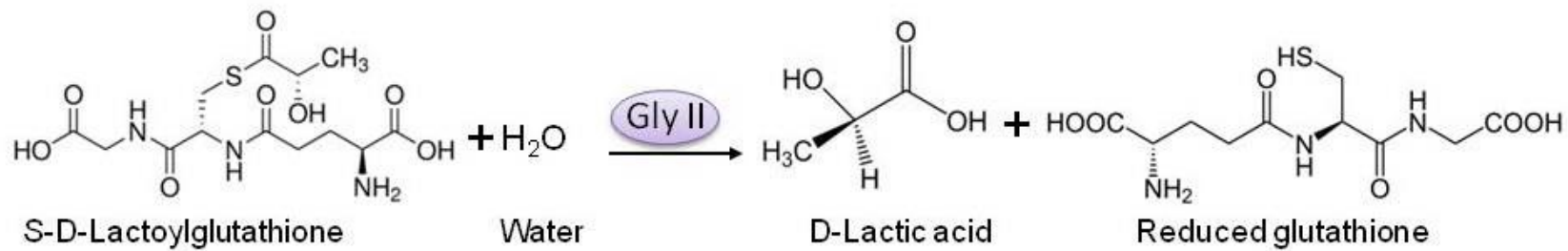

Fig 1. Mechanism of glyoxalase reaction to detoxify MG in living system.
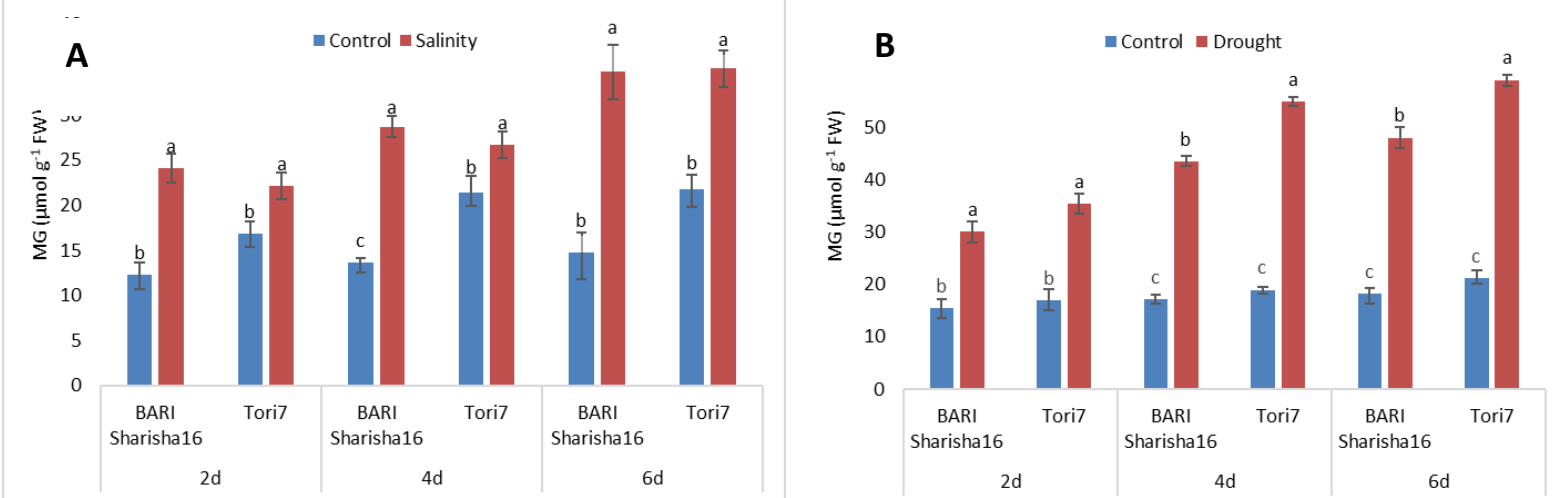

Fig 2. Changes in MG level under salinity (A) and drought (B) stress at 2, 4 and 6 days. Mean $( \pm \mathrm{SE})$ was calculated from three replicates for each treatment. Bars with different letters are significantly different at $\mathrm{P} \leq 0.05$ applying DMRT.
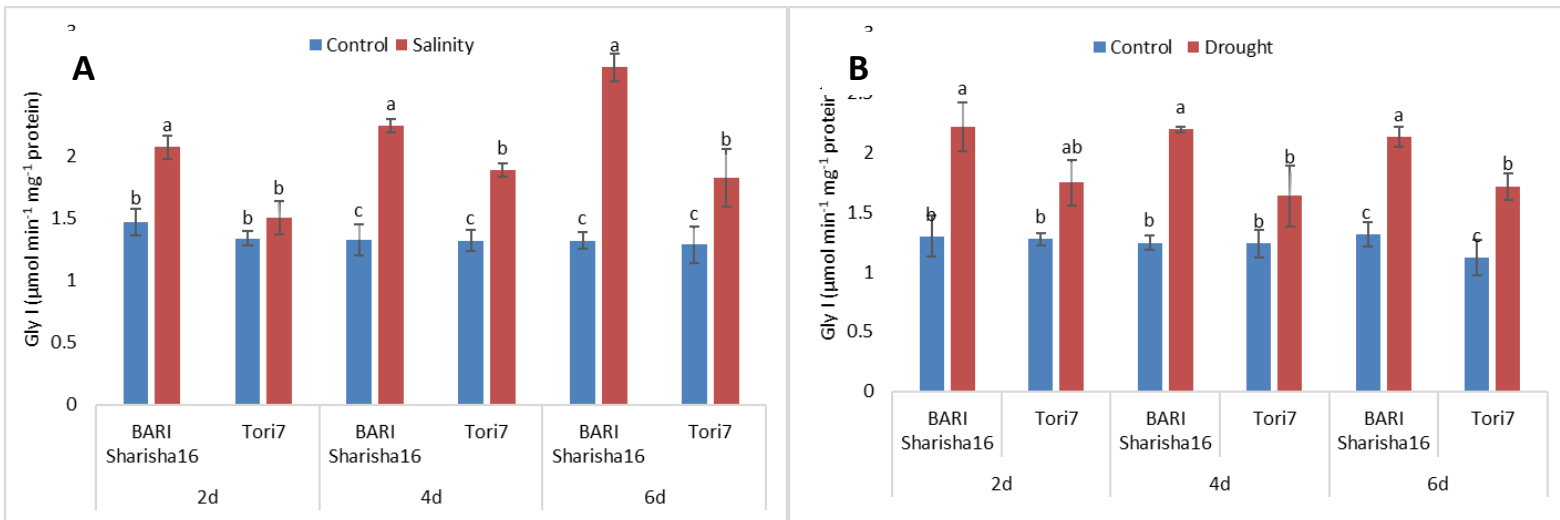

Fig 3. Changes in activity of Gly I under salinity (A) and drought (B) stress. Mean $( \pm$ SE) was calculated from three replicates for each treatment. Bars with different letters are significantly different at $\mathrm{P} \leq 0.05$ applying DMRT. 

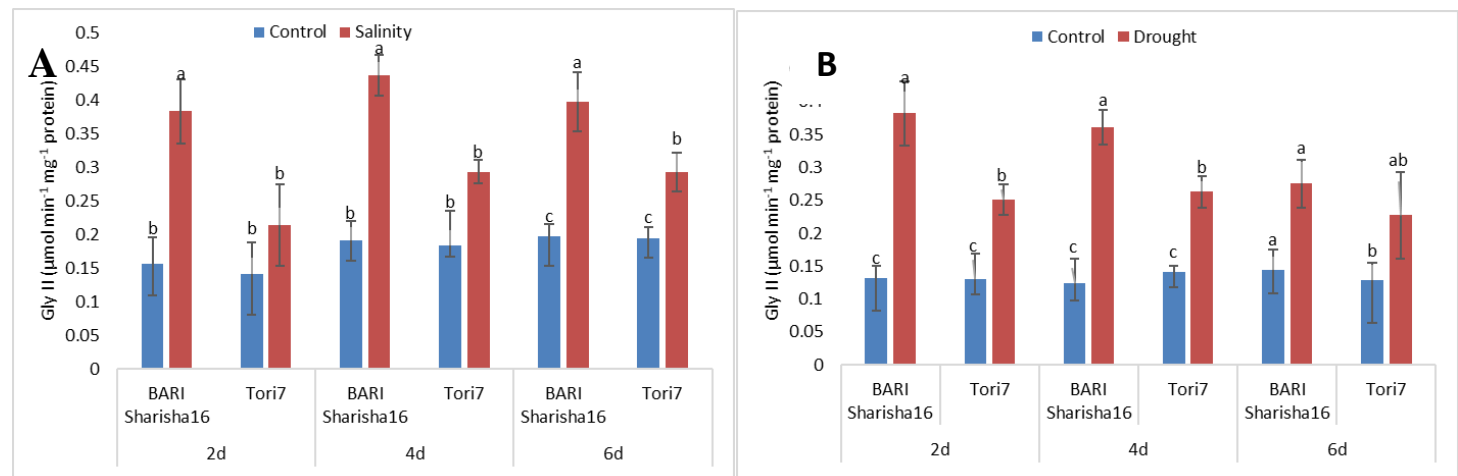

Fig 4. Changes in activity level of Gly II under salinity (A) and drought (B) stress. Mean $( \pm$ SE) was calculated from three replicates for each treatment. Bars with different letters are significantly different at $\mathrm{P} \leq 0.05$ applying DMRT.

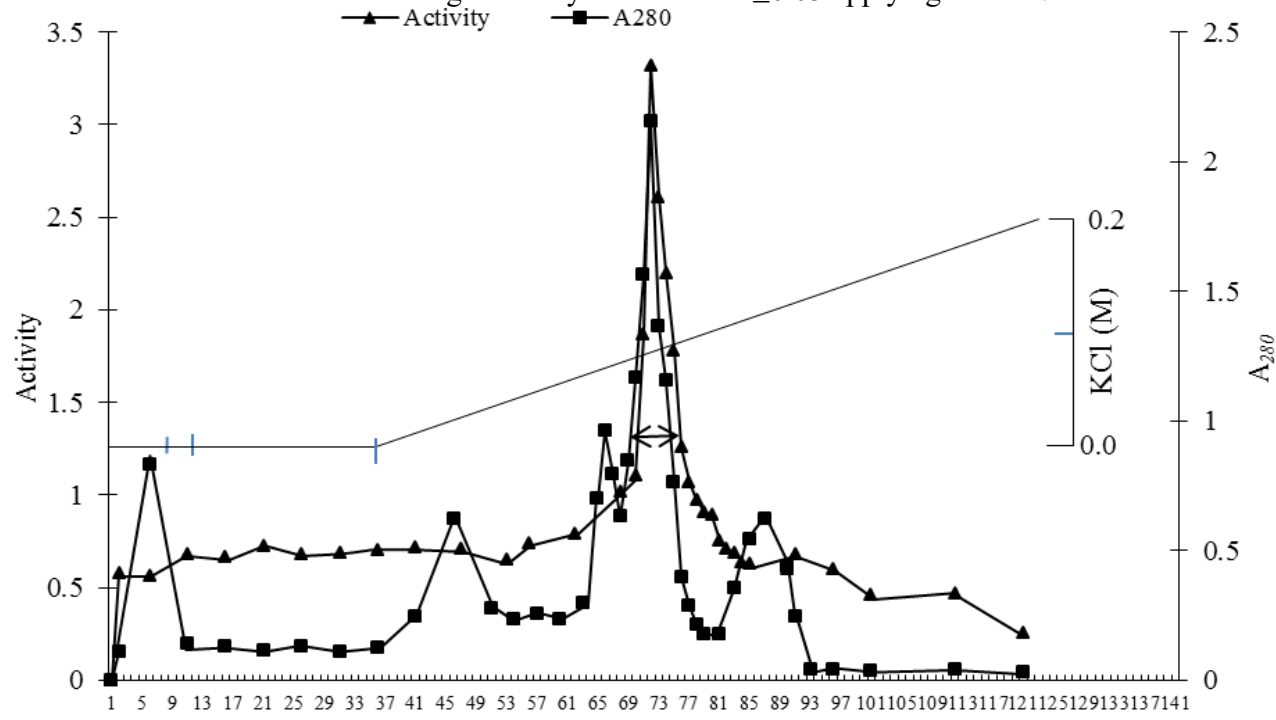

Fraction number

Fig 5. A typical DEAE-cellulose column chromatography of soluble crude protein prepared from $50 \mathrm{~g}$ fresh leaf of seedlings of BARI Sharisha16. For each fraction, absorbance at $280 \mathrm{~nm}(\boldsymbol{\bullet})$ and Gly I activity ( $\boldsymbol{\Delta}$ )were determined. Activity is expressed as $\mu \mathrm{mol}$ $\mathrm{min}^{-1} \mathrm{ml}^{-1}$. Bars indicate the high active peak fractions of Gly I. The fractions under the bar of Gly I, peak was pooled for subsequent purification. The curve shows the concentration of $\mathrm{KCl}(0-0.2 \mathrm{M})$.

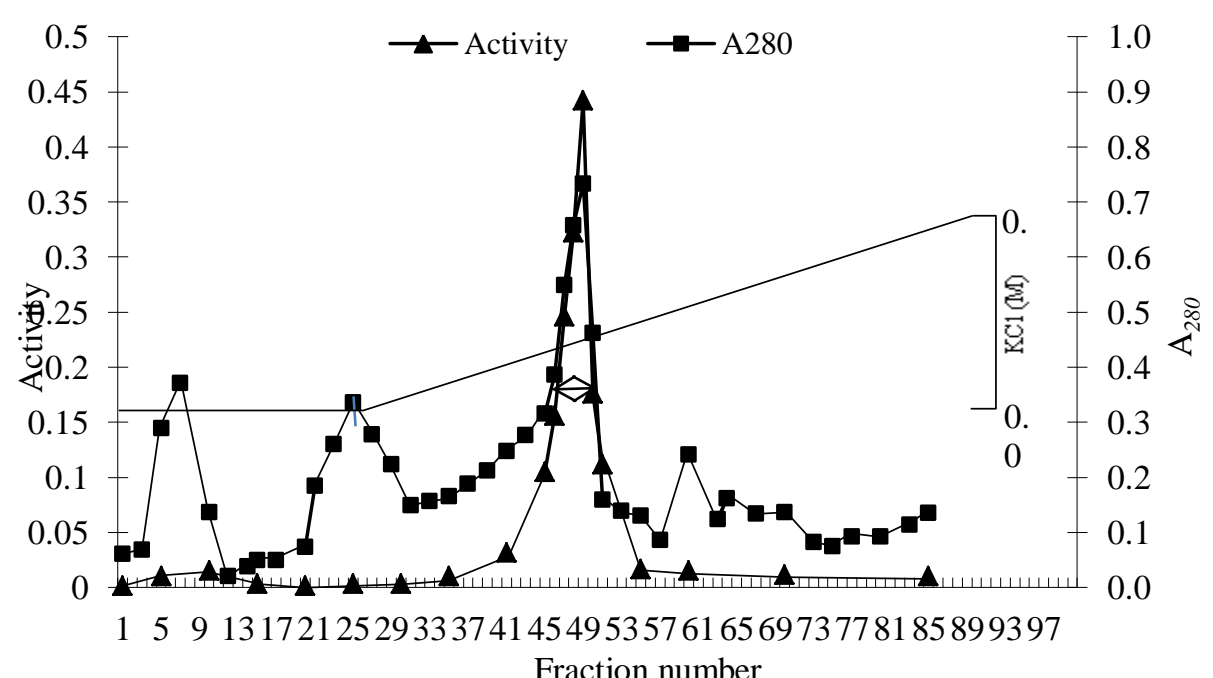

Fig 6. DEAE column-2 of Gly I pool from DEAE column-1. For each fraction, absorbance at $280 \mathrm{~nm}(\bullet)$ and Gly I activity were determined. Activity is expressed as $\mu \mathrm{mol} \mathrm{min} \mathrm{m}^{-1} \mathrm{ml}^{-1}$. Bars indicate the high active peak fractions of Gly I. The fractions under the bar of Gly I, peak was pooled for subsequent purification. The curve shows the concentration of $\mathrm{KCl}(0-0.2 \mathrm{M})$. 


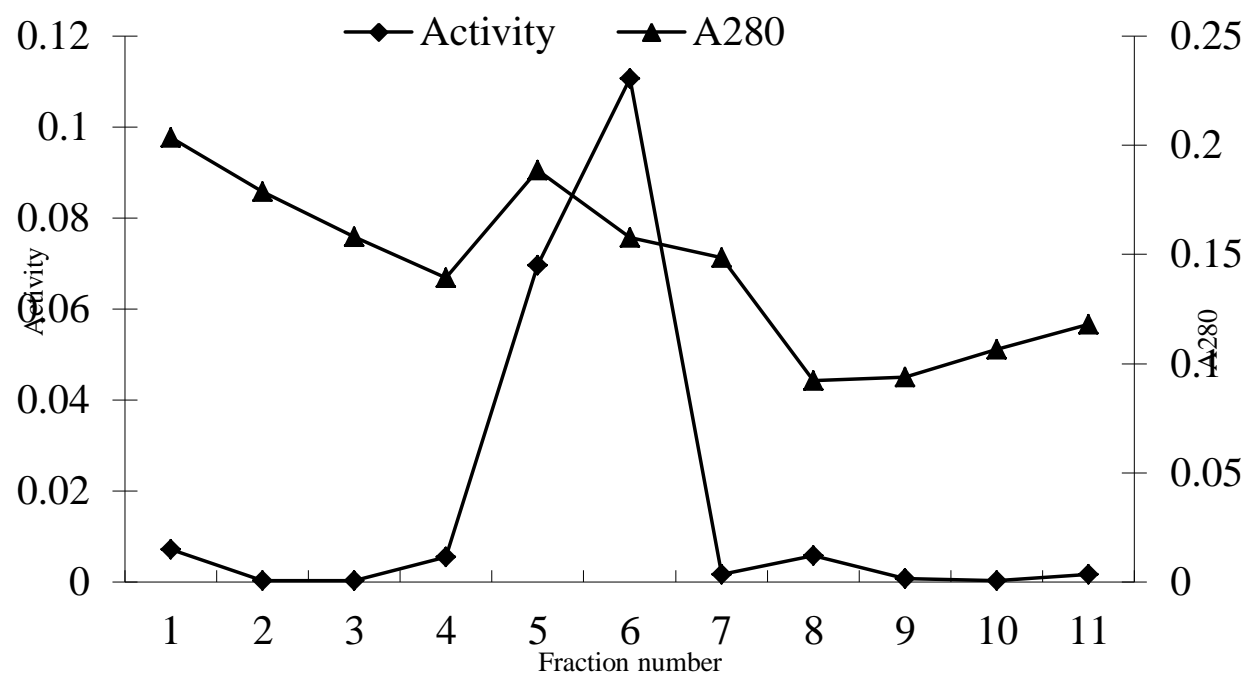

Fig 7. Elution profile of Gly I from affinity column chromatography ( $S$-hexylglutathione-agarose). The fractions were eluted by $S$ hexylglutathione. For each fraction, absorbance at $280 \mathrm{~nm}(\boldsymbol{\Delta})$ and Gly I activity $(\bullet)$ were determined. Activity is expressed as $\mu \mathrm{mol}$ $\min ^{-1} \mathrm{ml}^{-1}$.
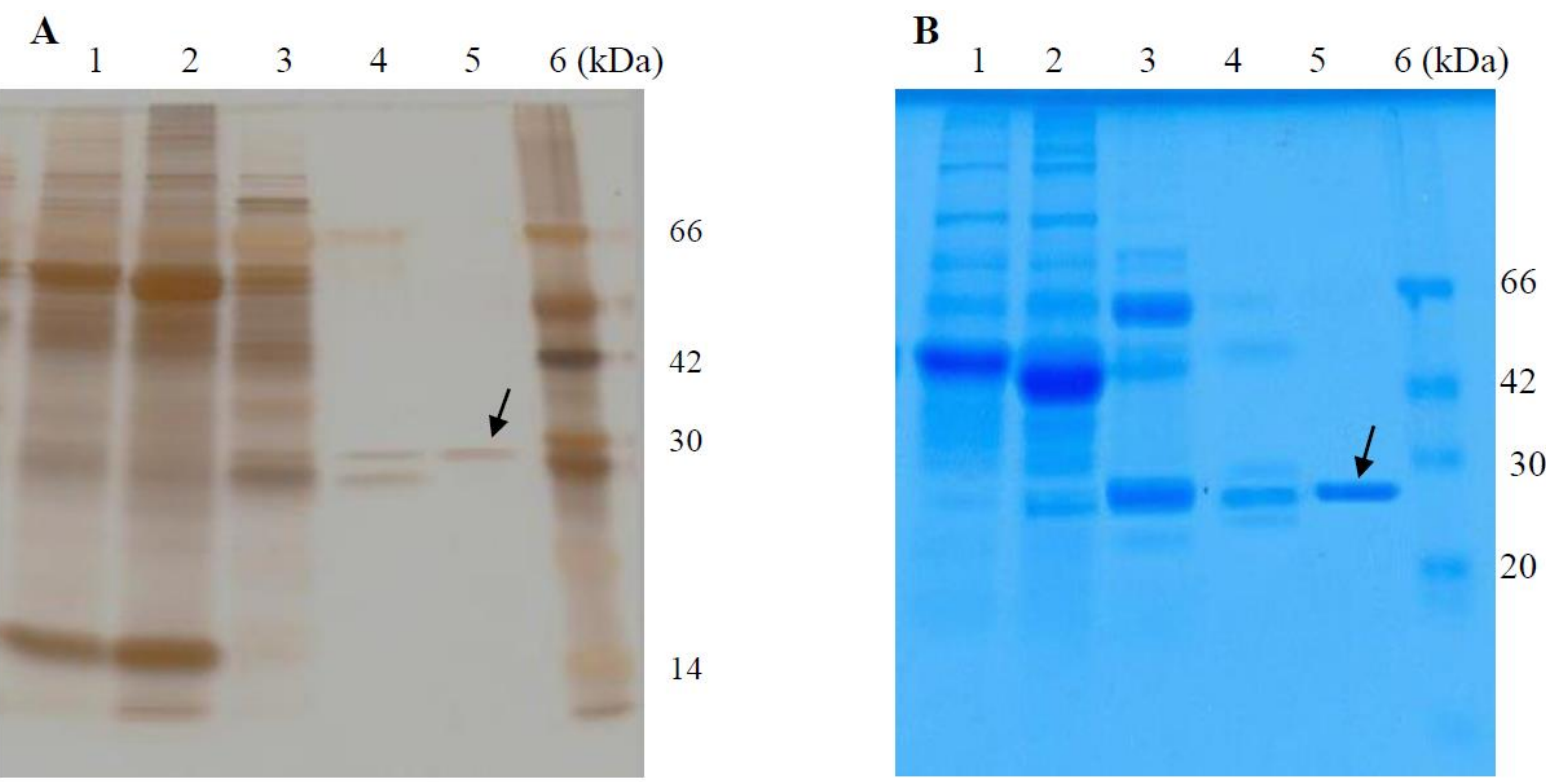

Fig 8. Silver staining (A) and $\mathrm{CBB}$ staining (B) of different fraction of Gly I purification from Brassica seedlings. Lane 1, Homogenous; Lane 2, $\left(\mathrm{NH}_{4}\right)_{2} \mathrm{SO}_{4} \mathrm{ppt}$; Lane 3, DEAE fraction-1; Lane 4, DEAE fraction-2; Lane 5, Purified Gly I; and Lane 6, Molecular weight.

glycolysis could generate MG (Kalapos, 1999; Vander et al., 2001; Distler et al., 2012). When plant exposed to stress conditions, enzymes of glycolysis and TCA cycles cells showed increased activity due to rapid functioning of cell (Umeda et al., 1994; Espartero et al., 1995; Sommer et al., 2001) and as a result increased triose phosphates are converted to MG instead of pyruvate only. So higher amount of methylglyoxal production under drought and salinity stresses confirmed by Hossain et al. (2009), Alam et al. (2014) and Nahar et al. (2015).

Various studies suggested a possible role of glyoxalase system in abiotic stress tolerance and also beneficial role in animal (Thornalley, 1993; 2003; Yadav et al., 2005b; ElShabrawi et al., 2010). Various exogenous factors affected the activity of Gly I (Deswal et al., 1993). Previously, Gly I from tomato was shown to be upregulated under salt and water stresses (Espartero et al., 1995; Hasanuzzaman et al., 2011a). In this study, Gly I activities were higher in BARI Sharisha16 than control and Tori7. Gly I activity increased $41 \%, 69 \%$ and $105 \%$ in BARI Sharisha16 whereas $12 \%, 43 \%$ and $41 \%$ in Tori7 under salinity condition (Fig 3A). These results suggested that the higher Gly I activity in BARI Sharisha16 is involved in tolerance through detoxification of high level of MG. This also suggested that the upregulation of Gly I may be a general effect in response to abiotic stresses to survive. Methylglyoxal, substrate of Gly I, is produced from triosephosphates, increased activity of Gly I might be required whenever the rates of glycolysis or photosynthesis are enhanced. Therefore, beside MG detoxification, the higher Gly I activities in BARI Sharisha16 and Tori7 might involve in different physiological process. Several research groups have reported that the activity of Gly I was affected by various abiotic stress treatments including salt, water and heavy metal stresses (Alam et al., 2014; Nahar 
et al., 2015; Rahman et al., 2015). The results of this study also addressed the situation.

Glyoxalase II converts the intermediate product produced by Gly I to D-lactate and release GSH to glutathione pool (Singla-Pareek et al. 2006, 2008). Therefore, in stress environment it plays important role in MG detoxification and GSH maintenance as well. In response to salinity stress and water stress, Gly II activity increased in BARI sharisha16 and Tori7 at 2, 4 and 6- day stress (Fig 4A, B). Previously salt sensitive BRRI dhan 49 was reported to show slight increase in the activity of Gly II and conversely, in salt tolerant BRRI dhan54 treatment with 150 and $300 \mathrm{mM} \mathrm{NaCl}$ showed significant increase in Gly II activity as compared to control (Hasanuzzaman et al., 2014; Alam et al., 2013; Nahar et al., 2015). In this study, Gly II activity was found higher in BARI Sharisha16 than that in Tori7 suggesting that the MG detoxification ability in higher in BARI Sharisha16. On the other hand, GSH recycling ability might also be in higher BARI Sharisha16.

The specific activity of homogenous was $1.54 \mu \mathrm{mol}^{-1} \mathrm{mg}$ ${ }^{1}$ protein and purified sample was $174 \mu \mathrm{mol}^{-1} \mathrm{mg}^{-1}$ protein. Total activity of homogenous was $115.68 \mathrm{mmol} \mathrm{min}^{-1}$ protein whereas $0.44 \mathrm{mmol} \mathrm{min}^{-1}$ protein in purified sample as in Table 1. As the sample passed through the columns specific activity increased, total activity decreased as the different proteins were removed through successive use of column chromatography Fig. 8A, B. The purified Gly I on SDSPAGE appeared to be $27 \mathrm{kDa}$ protein. In purification, Gly I were found to be highly purified with purification fold 113 and recovery $0.38 \%$. Brassica Gly I had no isoforms (Veena et al., 1999). The size of the protein was in onion is $25 \mathrm{kDa}$ confirmed after SDS-PAGE (Hossain and Fujita., 2009). Gly I purified from soybean cell suspension showed 1000-fold with a yield of 3.5\% (Paulus et al., 1993). The Gly I purified was lined with in the sizes reported above.

\section{Materials and Methods}

\section{Plant material}

All plant materials, BARI sharisha16 and Tori7 were collected from the field laboratory of oil seed research centre, Bangladesh Agricultural Research Institute, Gazipur, Bangladesh.

\section{Stress treatments}

Seeds of BARI Sharisha16 (tolerant) and Tori7 (susceptible) were grown in pot under greenhouse conditions $\left(25^{\circ} \mathrm{C}\right.$ and $12 \mathrm{~h}$ photoperiod). Five-day-old seedlings were treated with $\mathrm{NaCl}$ solution to induce saline stress. The salinity level 16 $\mathrm{dSm}^{-1}$ was arisen by adding saline water prepared by $\mathrm{NaCl}$, and the concentration of salinity in soil was measured by electrical conductivity meter (Hanna, Hungary). For drought stress, 10-day seedlings were stopped watering to induce drought stress until wilting. For both cases, one set of untreated control seedlings were maintained in normal growing condition for both tolerant and susceptible genotypes. Data were taken after 2, 4 and 6 days of stress implementation. For purification of Gly I, seven-day old seedlings of BARI Sharisha16 were used.

\section{MG determination}

Methylglyoxal was estimated according to Rohman et al. (2016) using N-acetyl-L-cysteine.

\section{Extraction of enzyme}

Fresh leaves $(0.5 \mathrm{~g})$ from seedlings of different treatments were homogenized in an equal volume of $50 \mathrm{mM}$ potassium phosphate buffer ( $\mathrm{pH} 7.0$ ) containing $100 \mathrm{mM} \mathrm{KCl}, 1 \%$ (w/v) ascorbate and $10 \%(\mathrm{w} / \mathrm{v})$ glycerol with mortar and pestle. The homogenates squeezed in a nylon cloth and was centrifuged at $11,500 \times \mathrm{g}$ for $10 \mathrm{~min}$ and the supernatant was used as soluble protein solution.

\section{Glyoxalase I assay}

Glyoxalase I assay was carried out according to the method of Islam et al. (2015) with slight modification. Briefly, the assay mixture contained $100 \mathrm{mM}$ sodium phosphate buffer ( $\mathrm{pH}$ 7.5), $15 \mathrm{mM}$ magnesium sulphate, $1.7 \mathrm{mM}$ glutathione and $3.5 \mathrm{mM}$ MG. The reaction was started by the addition of enzyme solution. The formation of thioester was measured by observing absorption at $240 \mathrm{~nm}$ for $1 \mathrm{~min}$. The activity was calculated using the extinction coefficient of $2.37 \mathrm{mM}^{-1} \mathrm{~cm}^{-1}$.

\section{Glyoxalase II assay}

Glyoxalase II activity was determined according to the method of Hasanuzzaman et al. (2011b) by monitoring the formation of reduced glutathione (GSH) at $412 \mathrm{~nm}$ for $1 \mathrm{~min}$. The reaction mixture contained $100 \mathrm{mM}$ Tris- $\mathrm{HCl}$ buffer $(\mathrm{pH}$ 7.2), $0.2 \mathrm{mM}$ DTNB and $1 \mathrm{mM} S$-D-lactoylglutathione (SLG) in a final volume of $1 \mathrm{ml}$. The reaction was started by the addition of SLG and the activity was calculated using the extinction coefficient of $13.6 \mathrm{mM}^{-1} \mathrm{~cm}^{-1}$.

\section{Purification of Gly I}

\section{Extraction of crude protein}

Fifty grams of leaves of 8 day old seedlings of tolerant genotypes BARI sharisha 16 was homogenized in equal volume of $50 \mathrm{mM}$ potassium phosphate buffer $(\mathrm{pH} 7.0)$ containing $100 \mathrm{mM} \mathrm{KCl}, 1 \%$ (w/v) ascorbate and $10 \%(\mathrm{w} / \mathrm{v})$ glycerol with a waring blender. The homogenates squeezed in a nylon cloth and was centrifuged at $11,500 \times \mathrm{g}$ for $10 \mathrm{~min}$ and the supernatant was used as crude protein solution.

\section{Precipitation of soluble protein}

Protein in the soluble protein solution was precipitated with ammonium sulfate at $65 \%$ saturation. The proteins were dialyzed against $10 \mathrm{mM}$ Tris- $\mathrm{HCl}$ buffer $(\mathrm{pH}$ 8.0) that contained $0.01 \%(\mathrm{v} / \mathrm{v}) \beta$-mercaptoethanol and $1 \mathrm{mM}$ EDTA (buffer A) overnight. The dialyzate was diluted to $35 \mathrm{ml}$ with same buffer.

\section{Anion exchange chromatography}

The dialyzate prepared from precipitation solution was applied to a column $(1.77 \mathrm{~cm}$ i.d. $\times 20 \mathrm{~cm})$ of DEAE-cellulose (DE-52; Whatman, Kent, UK) that had been equilibrated with buffer A. This was termed as DEAE-cellulose chromatography-1. The column was washed with buffer A, and eluted with a linear gradient of 0 to $0.2 \mathrm{M} \mathrm{KCl}$ in $800 \mathrm{ml}$ of buffer A. High active fractions of $5.0 \mathrm{ml}$ were collected. The activity and absorbance $\left(\mathrm{A}_{280}\right)$ of each fraction were measured spectrophotometrically.

The fractions corresponding to the high Gly I active peaks were combined as the Gly I pool for further purification. The pooled Gly I sample was applied on another DEAE-cellulose 
chromatography (termed as DEAE-cellulose chromategraphy-2) and eluded with same gradient solution $(600 \mathrm{ml})$. High actine Gly I fractions, each containing $5 \mathrm{ml}$, were collected and subjected to measure activity and absobance $\left(\mathrm{A}_{280}\right)$. High Gly $\mathrm{I}$ fractions were pooled for further purification by affinity chromatography to complete the purification.

\section{Affinity chromatography}

The high active Gly I peak of anion exchange chromatography-2 were applied to a column $(0.76 \mathrm{~cm}$ i.d. $\times 4.0 \mathrm{~cm}$ ) of $S$-hexylglutathione-agarose (Sigma, St. Louis, MO) that had been equilibrated with $10 \mathrm{mM}$ Tris-HCl buffer $(\mathrm{pH}$ 8.0) containing $0.01 \%(\mathrm{v} / \mathrm{v}) \beta$-mercaptoethanol (buffer B). The column was washed with buffer B containing $0.2 \mathrm{M}$ $\mathrm{KCl}$ and eluted with buffer B containing $1.2 \mathrm{mM} S$ hexylglutathione. Fractions of $2.5 \mathrm{ml}$ were collected. Protein fractions eluted with Gly I were combined and dialyzed against buffer B. The dialysate was used as the purified Gly I solution.

\section{Protein quantification}

The protein concentration of each sample was determined by the method of Bradford (1976) using BSA as protein standard.

\section{SDS-PAGE and Silver Staining}

To check the homogeneity of the purified enzyme and to estimate its molecular mass SDS-PAGE was done in $12.5 \%(\mathrm{w} / \mathrm{v})$ gel containing $0.1 \%(\mathrm{w} / \mathrm{v})$ SDS by the method of Laemmli (1970) followed by silver staining.

\section{CBB Staining}

To visualize enzyme, the gel was shacked in concentrated CBB solution overnight. On next day, the gel was destained and scanned.

\section{Measurement of molecular weight}

The Molecular weight was measure by gel documentation system (Alpha-Inotech)

\section{Data analysis}

Data generated from this study were analyzed by STATISTIX 10 software where need. Data were analyzed following CRD design with three replications. Means were separated by Dancan's Multiple Range Test (DMRT) test and $\mathrm{P} \leq 0.05$ was considered as significance level. The graphs were prepared in MS Excel, 2010. Mean values \pm standard error (SE) were presented in graphs from at least three independent experiments, each containing three replications.

\section{Conclusion}

Glyoxalase system is known to play a very important role in abiotic stress tolerance. This two-step pathway detoxifies ubiquitously present cytotoxic metabolite MG, which otherwise increases to lethal concentrations under various stress conditions. In this study, role of glyoxalase system in detoxification of MG was observed and subsequent purification of a high active Gly I enzyme from tolerance plants. Further research will be conducted with this purified
Gly I to examine its accumulation in plants under abiotic stress.

\section{Acknowledgement}

This research was funded by 'Improvement and quality seed Production of Rice, Wheat and Maize Project', Ministry of Agriculture, Bangladesh. We are also thankful to Mr. A F M Shamin Ahsan and Md. Ahsan Ullah for their cooperation during this research.

\section{References}

Alam MM, Hasanuzzaman M, Nahar K, Fujita M (2013) Exogenous salicylic acid ameliorates short-term drought stress in mustard (Brassica juncea L.) seedlings by upregulating the antioxidant defense and glyoxalase system. Aust J Crop Sci. 7(7): 1053-1063.

Alam MM, Nahar K, Hasanuzzaman M, Fujita M (2014) Trehalose-induced drought stress tolerance: A comparative study among different Brassica species. Plant Omics. 7(4):271-283

Bradford MM (1976) A rapid and sensitive method for the quantitation of microgram quantities of protein utilizing the principle of protein-dye binding. Anal Biochem. 72(12):248-254.

Deswal R, Chakaravarty TN, Sopory SK (1993) The glyoxalase system in higher plants: regulation in growth and differentiation. Biochem Soc Trans. 21(2): 527-530.

Distler MG, Palmer AA (2012) Role of Glyoxalase1 (Glo1) and methylglyoxal (MG) in behavior: recent advances and mechanistic insights. Front Genet. 3: article 250 doi: $10.3389 / .2012 .00250$.

El-Shabrawi H, Kumar B, Kaul T, Reddy MK, Singla-Pareek SL, Sopory SK (2010) Redox homeostasis, antioxidant defense, and methylglyoxal detoxification as markers for salt tolerance in Pokkali rice. Protoplasma. 245(1):85-96.

Espartero J, Sanchez-Aguayo I, Pardo JM (1995) Molecular characterization of glyoxalase-I from a higher plant: upregulation by stress. Plant Mol Biol. 29(6): 1223-1233.

Hasanuzzaman M, Alam MM, Rahman A, Hasanuzzaman M, Nahar K, Fujita M (2014) Exogenous proline and glycine betaine mediated upregulation of antioxidant defense and glyoxalase systems provides better protection against saltinduced oxidative stress in two rice (Oryza sativa L.) varieties. Biomed Res Int. Article ID 757219, 17 pages http://dx.doi.org/10.1155/2014/757219.

Hasanuzzaman M, Hossain MA, Fujita M (2011a) Nitric oxide modulates antioxidant defense and the methylglyoxal detoxification system and reduces salinity-induced damage of wheat seedlings. Plant Biotechnol Report. 5(4): 353365.

Hasanuzzaman M, Hossain MA, Fujita M (2011b) Seleniuminduced up-regulation of the antioxidant defense and methylglyoxal detoxification system reduces salinityinduced damage in rapeseed seedlings. Biol Trace Elem Res. 143(3): 1704-1721.

Hoque MA, Banu MNA, Nakamura Y, Shimoishi Y, Murata Y (2007) Proline and glycinebetaine enhance antioxidant defense and methylglyoxal detoxification systems and reduce $\mathrm{NaCl}$-induced damage in cultured tobacco cells. J Plant Physiol. 165(8): 813-824.

Hossain MA, Fujita M (2009) Purification of glyoxalase I from onion bulbs and molecular cloning of its cDNA. Biochem Soc Trans.73(9): 2007-2013. 
Hossain MA, Hossain MZ, Fujita M (2009) Stress-induced changes of methylglyoxal level and glyoxalase I activity in pumpkin seedlings and cDNA cloning of glyoxalase-I gene. Aust J Crop Sci. 3(2): 53-64.

Islam MR, Chowdhury AK, Rahman MM, Rohman MM (2015) Comparative Investigation of Glutathione $S$ transferase (GST) in Different Crops and Purification of High Active GSTs from Onion (Allium cepa L.). J Plant Sci. 3(3): 162-170. doi: 10.11648/j.jps.20150303.17

Kalapos MP (1999) Methylglyoxal in living organisms Chemistry, biochemistry, toxicology and biological Implications. Toxicol Lett.110:145-175.

Kaur C, Mustafiz A, Sarkar A, Ariyadasa TU, Singla-Pareek SL, Sopory SK (2014) Expression of abiotic stress inducible ETHE1-like protein from rice is higher in roots and is regulated by calcium. Physiol Plant. 152(1):1-16. doi: $10.1111 / p p l .12147$.

Kumar V, Yadav SK (2009) Proline and betaine provide protection to antioxidant and methylglyoxal detoxification systems during cold stress in Camellia sinensis (L.) O. Kuntze. Acta Physiol Plant.31: 261-269.

Laemmli UK (1970) Cleavage of structural proteins during the assembly of head of bacteriophage T4. Nature. 227: 680-685

Nahar K, Hasanuzzaman M, Alam MM, Rahman A, Suzuki T, Fujita M (2016) Polyamine and nitric oxide crosstalk: Antagonistic effects on cadmium toxicity in mung bean plants through upregulating the metal detoxification, antioxidant defense and methylglyoxal detoxification systems. Ecotoxicol Environ Saf. 126: 245-255

Nahar K, Hasanuzzaman M, Alam MM, Fujita M (2015) Roles of exogenous glutathione in antioxidant defense system and methylglyoxal detoxification during salt stress in mung bean and methylglyoxal detoxification during salt stress in mung bean. Biol Plant. 59 (4): 745-756.

Paulus C, Kollner B, Jacobsen HJ (1993) Physiological and biochemical characterization of glyoxalase I, a general marker for cell proliferation, from a soybean cell suspension. Planta. 189(4): 561-566.

Rahman A, Mostofa MG, Nahar K, Hasanuzzaman M, Fujita M (2015) Exogenous calcium alleviates cadmium-induced oxidative stress in rice (Oryza sativa L.) seedlings by regulating the antioxidant defense and glyoxalase systems. Braz J Bot. DOI 10.1007/s40415-015-0240-0.

Rohman MM, Begum S, Talukder MZA, Akhi AH, Amiruzzaman M, Ahsan AFMS, Hossain Z (2016) Drought sensitive maize inbred shows more oxidative damage and higher ROS scavenging enzymes, but not glyoxalases than a tolerant one at seedling stage. Plant Omics J, 9(4): 220232.

Saxena M, Roy SB, Singla-Pareek SL, Sopory SK, BhallaSarin N (2011) Overexpression of the Glyoxalase II gene leads to enhanced salinity tolerance in Brassica juncea. Open Plant Sci J. 5: 23-28.
Silva MS, Gomes RA, Ferreira AEN, Freire AP, Cordeiro C (2013) The glyoxalase pathway: the first hundred years . . and beyond. Biochem J. 453:1-15 (Printed in Great Britain) doi:10.104 2/BJ20121743

Singla-Pareek SL, Yadav SK, Pareek A, Reddy MK, Sopory SK (2006) Transgenic tobacco overexpressing glyoxalase pathway enzymes grow and set viable seeds in zinc-spiked soils. Plant Physiol. 140(2):613-623.

Singla-Pareek SL, Yadav SK, Pareek A, Reddy MK, Sopory SK (2008) Enhancing salt tolerance in a crop plant by overexpression of glyoxalase II. Transgenic Res. 17(2): 171-180.

Sommer A, Fischer P, Krause K, Boettcher K, Brophy PM, Walter RD, Liebau E (2001) A stress-responsive glyoxalase I from the parasitic nematode Onchocerca volvulus. Biochem J. 353(pt3): 445-452.

Thornalley PJ (1993) The glyoxalase system in health and disease. Mol Aspects Med. 14(4):287-371.

Thornalley PJ (1998) Glutathione-dependent detoxification of $\alpha$-oxoaldehyde by the glyoxalase system: involvement in disease mechanisms and antiproliferative activity of glyoxalase I inhibitors. Chem Biol Interact. 111-112: 137151

Thornalley PJ (2003) Glyoxalase-I structure, function and a critical role in the enzymatic defence against glycation. Biochem Soc Trans. 31(pt6):1343-1348

Umeda M, Hara C, Matsubayashi Y, Li HH, Liu Q, Tadokoro F, Aotsuka S, Uchimiya H (1994) Expressed sequence tags from cultured cells of rice (Oryza sativa L.) under stressed conditions: analysis of transcripts of genes engaged in ATP-generating pathways. Plant Mol Biol. 25(3):469-478.

Vander Jagt DL, Hassebrook RK, Hunsaker LA, Brown WM, Royer RE (2001) Metabolism of the 2-oxoaldehyde methylglyoxal by aldose reductase and by glyoxalase-I: roles for glutathione in both enzymes and implications for diabetic complications. Chem Biol Interact. 130-132: 549562

Veena, Reddy VS, Sopory SK (1999) Glyoxalase I from Brassica juncea: molecular cloning, regulation and its over-expression confer tolerance in transgenic tobacco under stress. Plant J. 17(4): 385-395.

Yadav SK, Singla-Pareek SL, Ray M, Reddy MK, Sopory SK (2005a) Methylglyoxal levels in plants under salinity stress are dependent on glyoxalase I and glutathione. Biochem Biophys Res Commun. 337:61-67.

Yadav SK, Singla-Pareek SL, Ray M, Reddy MK, Sopory SK (2005b) Transgenic tobacco plants overexpressing glyoxalase enzymes resist an increase in methylglyoxal and maintain higher reduced glutathione levels under salinity stress. FEBS Letters. 579(27): 6265-6271. 